Article

\title{
Evaluating a Workflow Tool for Simplifying Scenario Planning with the Online WhatIf? Planning Support System
}

\author{
Muhammad Qadeer ul Hussnain ${ }^{1, * \mathbb{C}}$, Abdul Waheed ${ }^{1}$, Khydija Wakil ${ }^{1}$, Junaid Abdul Jabbar ${ }^{2}$, \\ Christopher James Pettit ${ }^{3}{ }^{(1)}$ and Ali Tahir ${ }^{2}(\mathbb{D}$ \\ 1 Department of Urban \& Regional Planning, National University of Science \& Technology (NUST), \\ Islamabad 44000, Pakistan; drwaheed@nit.nust.edu.pk (A.W.); khydijawakeel.urp@nit.nust.edu.pk (K.W.) \\ 2 Institute of Geographical Information Systems, National University of Science \& Technology (NUST), \\ Islamabad 44000, Pakistan; jjabbar@igis.nust.edu.pk (J.A.J.); ali.tahir@igis.nust.edu.pk (A.T.) \\ 3 City Futures Research Centre, Built Environment, University of New South Wales, Sydney 2052, Australia; \\ c.pettit@unsw.edu.au \\ * Correspondence: plannerqadeer.urp@nit.nust.edu.pk; Tel.: +92-334-966-9884
}

Received: 23 October 2020; Accepted: 22 November 2020; Published: 26 November 2020

\begin{abstract}
In an era of smart cities and digitalisation, there has been a noticeable increase in the development and application of planning support systems (PSS). However, a significant challenge in the broader adoption of these PSS can be attributed to the user experience, which includes the efforts required in pre-processing data. It has been observed that typically $80 \%$ of the PSS usage time goes into pre-processing, cleaning, and loading data-a significant barrier for new users. This research focuses on improving user experience by developing and evaluating a new workflow tool called EasyUAZ. This workflow tool directly supports the iterative data preparation needs of scenario planning with the Online WhatIf?-a widely used PSS to develop land-use suitability, demand and land-allocation scenarios. A comparative evaluation has been conducted to quantify the time taken for data preparation with ArcGIS, QGIS, and the EasyUAZ. The study found that EasyUAZ offers a time saving of $30 \%-35 \%$ when compared with other options.
\end{abstract}

Keywords: uniform analysis zone; UAZ; Online WhatIf?; planning support systems; data preparation; workflow tools; PSS; SDSS; scenario planning

\section{Introduction}

The interdependence of transportation, environment, land use, and other socioeconomic factors has made urban planning a complex, dynamic, and highly subjective process. In today's body of knowledge, many GIS-based planning support systems (PSS) exist, which can not only be used to formulate scenario-based alternatives but can be used to evaluate and validate urban plans. Russo has documented more than 100 planning support systems, some of which are open-sourced and are available as freeware [1,2]. However, these tools' adoption and application have been slow [3-6]. The investigation of the reasons behind low utilisation identifies difficulties in data preparation as a major cause [7]. When the flow from data to data-driven urban planning is explored, two significant stages of bottlenecks can be identified; (i) the challenges which hinder the effective utilisation of data in PSS tools and create the barrier of perceived complexity in new users while initiating the use of PSS and (ii) the challenges which hinder the adoption of PSS tools (see Figure 1). A group of scholars has extensively highlighted the bottlenecks affecting the widespread adaptation and usage of planning support systems and digital planning tools in the real-world planning [3,6,7]. Their work is primarily focused on stage 2 bottlenecks, where they try to explore the mismatch between what 
planning support tools are offering versus what is need by the planners. After the increased availability of big and complex datasets, there is a need to focus on the stage 1 bottleneck as well, so that the available information can be truly harnessed and put into meaningful action by the planning support tools. This research is focused on the stage 1 bottleneck. Hence, the overall aim of this research is to investigate if workflow tools can assist in reducing the barriers of adoption for new PSS users by simplifying data pre-processing needs.

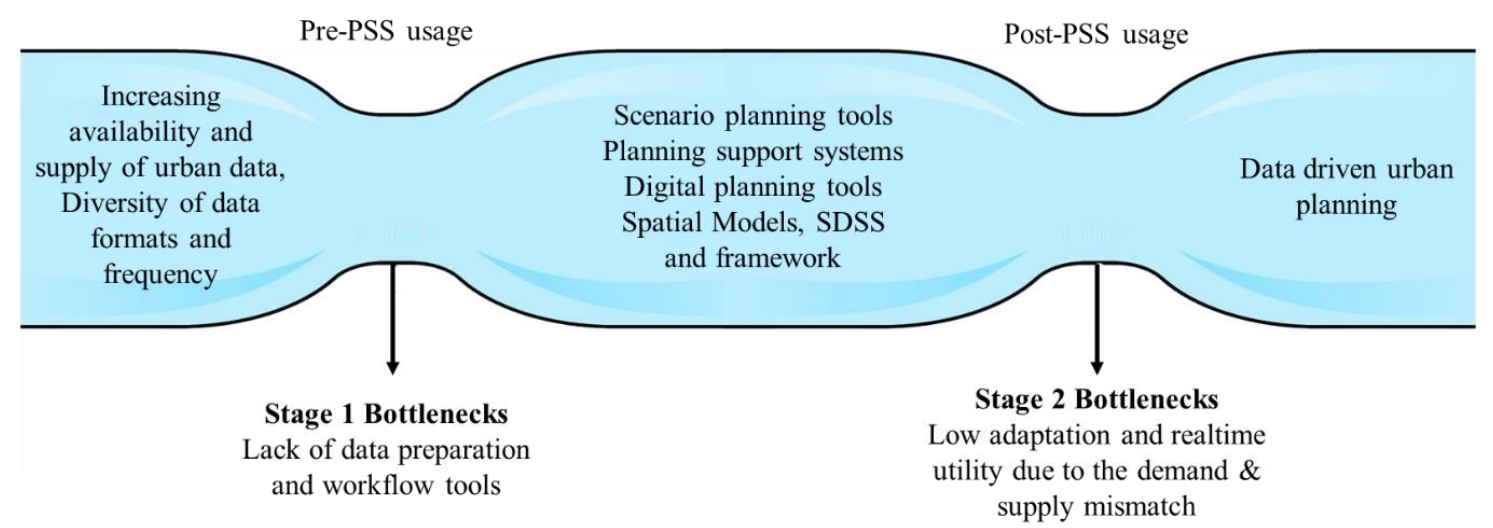

Figure 1. Key stages of bottlenecks from data to data-driven planning.

Despite their usefulness, many of the well-documented PSS such as UrbanSim [8] Metronamica [9], SLEUTH [10], and CommunityViz [11] have been critiqued for being relatively complex. These PSS tools require high levels of training and experience to run, take a significant amount of data, and need extensive data cleaning and pre-processing [12-14]. It is estimated that $80 \%$ of the PSS utilisation time goes into data pre-processing and refining the data information structure $[15,16]$. A decade ago, while documenting their PSS, Rainis et al. also highlighted its limitation for data pre-processing and high dependency on other GIS tools [17]. The data preparation becomes more intense in the scenario planning process, which demands iterations and frequent data changes during execution [18-20]. Holway et al. (2012) highlighted that data acquisition, usage, and interoperability are major stumbling blocks in opening access to the scenario planning tools [5].

Online WhatIf? (OWI) is one of the most prominent open-sourced PSS tools, developed and managed by Australian Urban Research Infrastructure Network (AURIN), used in over 22 countries by more than 250 international users and academically published for suitability analysis, demand analysis and allocation analysis in spatial planning scenarios [2,7,21-26]. Currently, the process of data preparation for Online WhatIf? requires the use of geospatial analysis using desktop GIS tools. While the researchers have extensively documented the benefits of Online WhatIf? in exploring scenarios for spatial plan making [4,21,22,25-32], some have indicated the burden of extensive data preparation. As the use cases have increased, the demand for a data processing workflow tool has arrived $[27,28]$. Rainis et al. had hoped that the limitations for data pre-processing and dependency in external GIS tools would be overcome with future development in the GIS industry [17]. However, despite fast-paced growth in the PSS domain, the paucity of pre-processing tools still prevails. The next section expresses the current state of data pre-processing and workflow tools in detail. It can be witnessed that there exists a dearth of workflow tools for PSS, which is primarily due to the diversity and choice-driven inherited demand of PSSs, not always offered by generic tools.

This research reviews the state of the art of data pre-processing tools and presents a classification template. It addresses the critical question of how the time efficiency can be ensured in data preparation time for a specific PSS by employing a customised workflow tool. It highlights the importance of data preparation and workflow tools as complementary products to well established planning support systems. Considering the concepts of task-technology fit [3,33-35], usefulness and added value of PSS [13], this study presents the designing, building, and testing of a data preparation workflow tool for the Online WhatIf? PSS. The experimental design of this research takes the form of a case study 
approach where the workflow tool is applied and evaluated in the context of formulating a spatial plan for the city of Faisalabad in Pakistan.

\section{State of the Data Pre-Processing and Workflow Tools}

With the recent rise of big and complex datasets [36,37], the need for workflow and pre-processing tools has become increasingly important. Furthermore, with the rapid growth of new data sources available to support urban modelling and data-driven decision-making [38-40], data cleaning and processing have appeared as more critical tasks requiring improved efficiency. While the concept of workflow tools has been primarily in business automation for the last many decades [41], it has been extensively adopted in the domain of GIS. However, there has been limited development of such workflow tools in the field of PSS.

Generic data pre-processing and workflow tools can assist in various processing needs ranging from simpler ETL operations (extract, transform, and load) to more complex workflow tasks spanning over heterogeneous applications. From the perspective of planning support science, we may categorise workflow tools in four categories (see Figure 2):

\begin{tabular}{|c|c|c|c|c|}
\hline $\begin{array}{l}\text { Tool } \\
\text { Categories }\end{array}$ & $\begin{array}{l}\text { Tools for processing } \\
\text { heterogenous data (for } \\
\text { uniformity of format, } \\
\text { scale, projections etc.) }\end{array}$ & $\begin{array}{l}\text { Workflow Tools for } \\
\text { tasks automation } \\
\text { within same } \\
\text { Application }\end{array}$ & $\begin{array}{l}\text { Workflow Tools for } \\
\text { tasks automation } \\
\text { among heterogenous } \\
\text { Applications }\end{array}$ & $\begin{array}{l}\text { Workflow Tools for } \\
\text { processing to generate } \\
\text { input datasets for PSS }\end{array}$ \\
\hline $\begin{array}{l}\text { Proprietary } \\
\text { Tools }\end{array}$ & $\begin{array}{l}\text { 1. Microsoft Power BI } \\
\text { 2. Sisense }\end{array}$ & $\begin{array}{l}\text { 1. ArcGIS Workflow } \\
\text { Manager } \\
\text { 2. ArcGIS model builder }\end{array}$ & $\begin{array}{l}\text { 1. FME (Feature } \\
\text { Manipulation } \\
\text { Engine) }\end{array}$ & $\begin{array}{l}\text { 1. UrbanCanvas Modeler } \\
\text { for UrbanSim } \\
\text { 2. Overlay \& Map Compar- } \\
\text { ison Kit for Metronamica }\end{array}$ \\
\hline $\begin{array}{l}\text { Open Source } \\
\text { Tools }\end{array}$ & $\begin{array}{l}\text { 3. Google's OpenRefine } \\
\text { 4. Scatter, Clustering,0- } \\
\text { networking } \\
\text { 5. GeoKattle (spatial ETL) } \\
\text { 6. Talend Spatial }\end{array}$ & $\begin{array}{l}\text { 3. QGIS Processing } \\
\text { Framework } \\
\text { 4. Google Earth Engine }\end{array}$ & $\begin{array}{l}\text { 2. Hale Studio for } \\
\text { Geospatial data }\end{array}$ & $\begin{array}{l}\text { 3. ORCA for UrbanSim } \\
\text { 4. GeoDMS for LandUse } \\
\text { Scanner } \\
\text { 5. EasyUAZ for Online } \\
\text { Whatlf? (this study) }\end{array}$ \\
\hline $\begin{array}{l}\text { Key Processing } \\
\text { Needs }\end{array}$ & $\begin{array}{ll}\text { - } & \text { Generic tools } \\
\text { - } & \text { Predefined formats } \\
& \text { Able to read diverse } \\
\text { data sources }\end{array}$ & $\begin{array}{l}\text { - Standardization of } \\
\text { input and output } \\
\text { products }\end{array}$ & - Interoperability & $\begin{array}{l}\text { Ability to take varied } \\
\text { user choices and } \\
\text { iterative inputs }\end{array}$ \\
\hline
\end{tabular}

Figure 2. The categorisation of pre-processing and workflow tools.

\subsection{Tools for Pre-Processing Heterogeneous Data}

This group may refer to the data processing tools (spatial and non-spatial) related to building data pipeline and wrangling data. Such tools are generally focused on accessing data from multiple heterogeneous data stores and producing outputs with the uniform format, scale, and geographic projection, etc. Examples of these tools include Google OpenRefine [42-44], Scatter, Clustering, 0-Networking [45], GeoKattle [46], and Talend spatial extension. Furthermore, the more common proprietary tools include Microsoft PowerBI [47] and Sisense. The critical processing requirement behind these tools is the ability to read diverse data sources and formats.

\subsection{Tools for Task Automation within the Same Application}

This group includes the tools that are generally offered as developer libraries, extensions, or plugins of software packages. These tools allow access to the functions and tasks available within the specific application and allow the knitting of those functions via programming and/or graphic workflow interfaces. Notable examples include ArcGIS workflow Manager [48] and ArcGIS model builder [49] in the proprietary domain while QGIS Processing Framework [50] and Google Earth Engine [51] in the open-source domain. 


\subsection{Tools for Task Automation among Heterogeneous Applications}

In contrast to the second group, these tools offer workflow management among multiple heterogeneous applications. The most commonly used example is Feature Manipulation Engine (FME) [52], which is capable of integrating multiple applications to resolve a complex workflow. The strength of FME lies in its ability to talk to multiple software and communicate data between over 450 applications through a visual interface [53]. In contrast to the licensed tools, Hale Studio is an open-source option to migrate, integrate, or harmonise complex spatial data [54].

\subsection{Pre-Processing Workflow Tools to Generate Input Datasets for PSS}

This group includes the tools specifically designed to complement planning support systems by providing an assistive mechanism to generate PSS specific input datasets. The previous three tools' groups are not explicitly designed to support PSS. Instead, those are primarily meant for generic task solving. In contrast, the tools under the fourth group are very strongly linked to specific PSS nomenclature. The critical processing need for these tools is the ability to take varied user choices and iterative processes as inputs. For instance, UrbanCanvas Modeler for UrbanSim is a web-based platform to manage model data inputs and results. This proprietary tool offers workflow management for developing input data relevant to land use and future development $[55,56]$. On the other hand, ORCA is an open-sourced tool for data processing and orchestration to support UrbanSim, which allows the users to define dynamic data sources and explicitly connect them to processing functions. ORCA is a part of Urban Data Science Toolkit (UDST) [57].

There has been a lack of data preparation and workflow tools, even for prominent PSS, especially those in the open-sourced domain. For instance, SLEUTH accepts the input data in GIF image format, which requires transforming input layers into rasterised grids of the same extent, resolution, and geographic projection. However, data preparation has to been completed using external desktop tools $[10,58,59]$. In the case of UrbanSim, data can be loaded into the simulation framework using ORCA or Pandas Dataframes, which offers data connectivity modules to fetch data from multiple sources, including HDF5 files, CSV and Excel files, DBF databases, and others. However, these data preparation mechanisms do not have graphical user interfaces (GUIs) and require user familiarity with the Python programming language. To overcome this limitation, UrbanCanvas has been provided with a GUI in a browser interface which, unlike other UrbanSim components, is a subscription-based service [55,57].

Similarly, LandUse Scanner (another well-known PSS, also called Ruimtescanner) [60], which provides a framework for Land Use change modelling, uses GeoDMS as its modelling software to process, calculate with and visualise datasets. The preparatory work for the use of LandUse Scanner requires the setting up of configuration files using a declarative language. The graphical user interface of the GeoDMS allows users to configure data files [61], which can be considered as a built-in preparatory tool. On the other hand, proprietary tools such as Metronamica, Index, and CommunityViz have some form of inbuilt data preparation tools. Metronamica has pre-integrated tools to construct and amend spatial scenarios using its Overlay Tool and Map Comparison Kit [9,62-64]. INDEX Planbuilder [65,66], and CommunityViz [67] are based on ESRI' ArcGIS platform, which makes the tools convenient for users while preparing data and undertake spatial pre-processing.

In the discussion of workflow automation for PSS, tools in the second and third groups are more useful. For instance, FME has been used to integrate multiple software and input-output flow [52]. However, FME is particularly useful if the inputs-outputs are clearly defined, and the process is non-iterative with lesser user inputs in choice selection [52,68,69]. Similarly, ArcGIS Model Builder has been frequently used and cited in combination with Python-based applications to streamline the processes in geospatial analysis.

By virtue of its larger user base and applications, the Online Whatif? planning support system has been studied and reviewed from various dimensions. In the last five years, researchers have evaluated the usefulness of the Online WhatIf? and have presented ways to further improvise its 
utility. Hussnain et al. have presented the development of a mobile-based data collection module to collect primary data on urban indicators for the Online WhatIf? [26]. Hussnain et al. have documented the process of input data preparation and subsequent processing challenges during a real-life project highlighting the iterative nature of the looping processes of geometric and spatial analysis [28]. While comparing the multi-criteria evaluation (MCE) based PSS, Russo et al. (2018) have referred to the data preparation challenges concerning PSS usability [29]. Pettit et al. have highlighted the use of ArcGIS desktop to prepare input datasets while using the Online WhatIf? in building land use and transport scenarios in Australia. While appreciating the Online WhatIf? utility for planning support, Pettit et al. registered their concern that input datasets preparation had been a time-consuming process that had to be restarted with any change in the study area. Pettit et al. have highlighted the need for automated workflow tools, which might be implemented as a module to the Online WhatIf? or as a stand-alone supporting tool [27]. The critical data pre-processing requirement gap has been filled through this study.

\section{Materials and Methods}

\subsection{Data and Preparation Requirements for the Online Whatif? PSS}

This study focuses on developing and evaluating the EasyUAZ; a new data preparation workflow tool for improving the useability of the Online WhatIf? (OWI) PSS [25,70-73]. The Online WhatIf? is a widely used PSS used to support scenario planning for future urban growth of cities and regions. The Online WhatIf? comprises three key components (i) Land Suitability (iii) Land Demand, and (iii) Land Allocation [72]. A comprehensive array of datasets is required to generate future urban growth scenarios for a city. This data traditionally requires significant effort to collect, clean, and process before the three key components of the tool can be run [27].

The spatial data used by Online WhatIf? contains various geophysical and natural conditions (terrain, soil, land uses, population etc.), factorial information (proximity, services availability, growth priorities etc.), existing and proposed infrastructure and land use controls (zoning districts, planned land uses etc.) which are processed to generate a single polygonal input vector file. To summarise, the whole study area is divided into land units possessing homogeneity of all factors under consideration called Uniform Analysis Zones (UAZs). Since the basic spatial unit of analysis in Online WhatIf? is a polygon; each polygon must represent the parcel of land where each point has the same value for all attributes. In the current workflow of the Online WhatIf? the preparation of the UAZ file is an external process that may be performed using any desktop GIS application. Resultantly, the UAZ for the Online WhatIf? contains all the essential information required to execute land suitability, future demand and land use allocation analysis.

\subsection{Research Design}

This research follows a two-stage process to achieve the desired objectives, as shown in Figure 3. Stage 1 is the design stage, which covers the development of EasyUAZ. Stage 2 focuses on both the technical and user evaluation of the tool. In evaluating the EasyUAZ workflow tool, the evaluation method proposed by Russo et al. [4] has been adapted after contextualisation. While comparing the usability of PSS tools to complete a predefined task, Russo et al. [4] employed a group of six participants and monitored them under the lab environment during the task performance process. Furthermore, they have used the user experience (UX) questionnaire to document users' mental models and expectations [29]. 


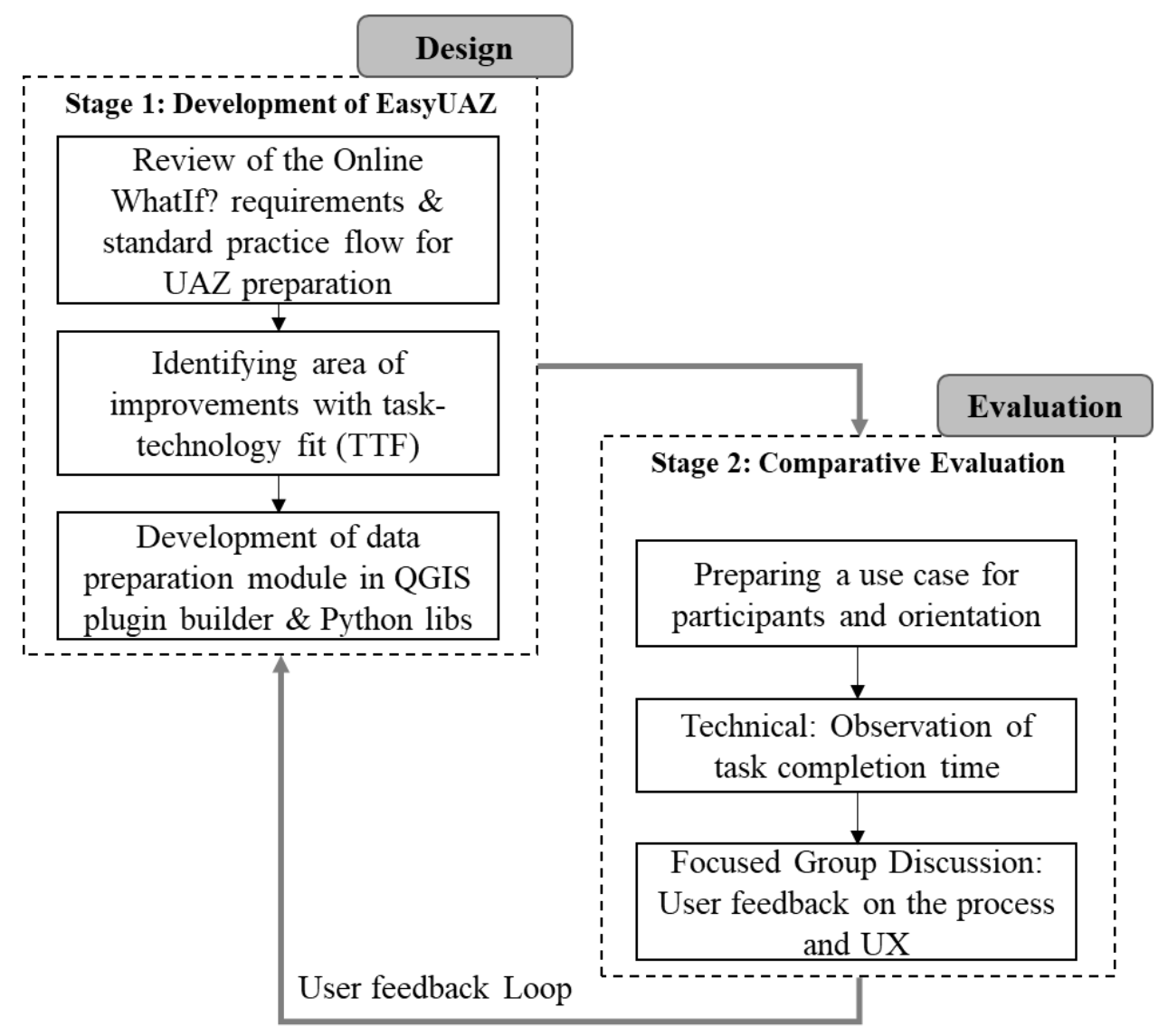

Figure 3. Research Methodology.

\subsection{Stage 1: Development of the EasyUAZ; a Preparatory Workflow Tool for Online WhatIf?}

Development of the EasyUAZ has been initiated with the review of the existing standard practice workflow of the Online WhatIf? user to generate UAZ (see Figure 4). It must be noticed that data preparation workflow is not just technical but involves discussions with key stakeholders to both negotiate data access and to determine acts of geoprocessing along with determining the factors (opportunity and constraints) which underpin the scenario planning process. This process is iterative and often needs revisiting in the scenario planning process if stakeholders wish to make changes to the input assumptions, later on, i.e., the new opportunity and constraint layers often need to be modified in the workflow tool. When users engage generic GIS tools for data preparation, the focus remains more on the technical aspects of geoprocessing rather than the dialogue between stakeholders on planning factors. Task Technology Fit (TTF is defined as the fit between PSS capacities (supply-side) and planning tasks (demand side)) Framework $[14,74]$ has been considered to see what processes can be automated so that the user may systematically interact with the factors (opportunity and constraints) which underpin the scenario planning process by focusing more on the factors and worry less about the background geo-processing. 


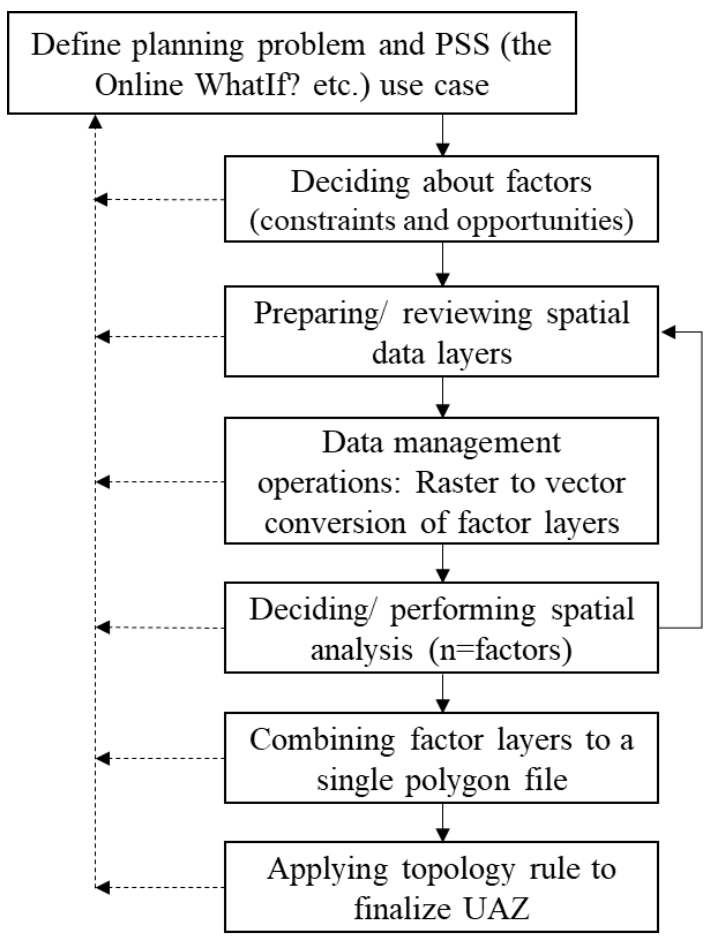

Figure 4. Standard practice workflow of an Online WhatIf? user to generate UAZ.

\subsection{Stage 2: Comparative Evaluation}

This research uses a combination of qualitative and quantitative approaches to evaluate the user experience; (a) technical (comparative analysis between tools for time evaluation), and (b) focus group discussion with participants on the strengths and weaknesses of the workflow tool in terms of ease of use and overall experience.

\subsubsection{User Experience (Technical)}

Pettit (2017) and Barton (2015) have used usability frameworks to explore user experience [75,76]. For time efficiency evaluation, the EasyUAZ tool has been compared with two other commonly used generic spatial data preparation tools; (a) ArcMap with spatial analyst [77] and (b) QuantumGIS (also known as QGIS) [78]. The newly developed tool (EasyUAZ) is the first of its kind to facilitate data processing for Online WhatIf? PSS. Traditionally, the data preparation for Online WhatIf? is done either by ArcGIS or QGIS. This research compares and explains how EasyUAZ can perform compared with the two for the specific case of Online WhatIf? users. It is essential to highlight that each of the other workflow tools in group 4 (as per Figure 2 such as UrbanCanvas, ORCA, GeoDMS) is specifically built to complement its respective PSS tools only including UrbanSim, and LanduseScanner, respectively. None of them can be used for the data preparation of other PSSs. In the given mutual exclusiveness, inter-PSS comparison of workflow tools has not been possible at the current situation. Consequently, this research focuses on comparing and understanding workflow improvement within EasyUAZ, ArcGIS and QGIS.

A team of 12 graduate planners (men $(n=9)$ and women $(n=3)$, age between 25 to 40 years) from the planning community of Punjab, Pakistan, have been engaged for the study. Participants had to meet the following criteria: (i) practising professional urban planner, (ii) experienced with GIS functions, including data management and spatial analysis, and (iii) proficiency in using ArcMap and QGIS.

This study adopted the within-subject design as recommended by Russo [4] and Graziano [79], where each participant used all three options to generate the desired UAZ but in a different order by considering all permutations $[29,79]$. Since we had three conditions to compare, the participants 
have been divided into six groups, who undertook the process in the order of $A B C, A C B, B A C, B C A$, $\mathrm{CAB}$, and CBA [80] (see Table 1). Each participant was asked to process only one workflow per day, considering the intensity of the task. Three identical workstations (screen size: 27 ", resolution: $1366 \times 768$, processor: Core i7, 7th Gen, 16GB SSD RAM with keyboard and mouse) have been used which were rotated such that three different participants in one day use each workstation, to keep uniformity in the processing power of the apparatus. The usage of workstations and participants were carefully scheduled such that each workstation could facilitate two distinct participants per day. As a result, the study was completed in three days. The processing time to prepare the UAZ was noted in minutes using the built-in stopwatch function of the workstation, which stayed hidden from the participants. The recording of the time was started from the moment of opening/running the understudy tool to its closure on a given workstation. For instance, if a user group (UG-1a) has been tasked to perform the UAZ preparation task on the workstation (ws1) using ArcMap; their time has been started from the moment they run ArcMap.exe on the ws1 and ends when they closes the project file after completing all the required task. The difference between the start and end time has been recorded in minutes. The colours in Table 1 give the visual representation to the counter-balanced order.

Table 1. The counter-balanced order adopted by participants to prepare UAZ with ArcMap, QGIS and EasyUAZ.

\begin{tabular}{ccccc}
\hline Participants & Order & Day 1 & Day 2 & Day 3 \\
\hline UG-1a & ABC & ArcMap-ws1 & QGIS-ws1 & EasyUAZ-ws1 \\
UG-2a & ACB & ArcMap-ws2 & EasyUAZ-ws2 & QGIS-ws2 \\
UG-3a & BAC & QGIS-ws1 & ArcMap-ws1 & EasyUAZ-ws1 \\
UG-4a & BCA & QGIS-ws3 & EasyUAZ-ws3 & ArcMap-ws3 \\
UG-5a & CAB & EasyUAZ-ws2 & ArcMap-ws2 & QGIS-ws2 \\
UG-6a & CBA & EasyUAZ-ws3 & QGIS-ws3 & ArcMap-ws3 \\
UG-1b & ABC & ArcMap-ws1 & QGIS-ws1 & EasyUAZ-ws1 \\
UG-2b & ACB & ArcMap-ws2 & EasyUAZ-ws2 & QGIS-ws2 \\
UG-3b & BAC & QGIS-ws1 & ArcMap-ws1 & EasyUAZ-ws1 \\
UG-4b & BCA & QGIS-ws3 & EasyUAZ-ws3 & ArcMap-ws3 \\
UG-5b & CAB & EasyUAZ-ws2 & ArcMap-ws2 & QGIS-ws2 \\
UG-6b & CBA & EasyUAZ-ws3 & QGIS-ws3 & ArcMap-ws3 \\
\hline$*$ A = ArcMap 10.5 with spatial analyst, B = Qunatum GIS 3.8, C = EasyUAZ, ws = workstation.
\end{tabular}

The participants were oriented about the Faislabad peri-urban plan and its data sets through a two-hour session. Table 1 provides the details of the datasets, its spatial type, and attribute classes. The task was to prepare a single polygonal—a UAZ file-which has the following characteristics:

- is free from geometric errors and comply with the topology rules of no overlaps, must not have gaps, and must not have slivers

- the factor layers need to be prepared and assigned to the main polygon file as columns containing required classes

To prepare the participants, they were informed that they would have to use the following spatial operations: service area analysis, multi-ring buffer analysis, natural neighbour interpolation, and spatial joining. Participants were informed that they could also perform other spatial analysis and data processing operations as they deemed appropriate using the tools available during the exercise.

\subsubsection{User Experience (Focused Group Discussion)}

In addition to the time recording, users were asked to share their feedback in a moderated focused group discussion which occurred on day 4 . The participants of the focused group discussion included the same users who tested the tools in the first place in the previous experiment. The active discussion spanned over $2 \mathrm{~h}$; however, once the note-taking was complete, some additional time was spent 
on ensuring that the feedback has been recorded in the exact sense as perceived by the experiment participants. The discussion revolved around documenting: (a) the most relevant experiences while engaging with different tools (ArcGIS, QGIS and EasyUAZ), (b) the extent to which features and the functions in the tools under comparison have been satisfactory for UAZ preparation and (c) the key most positive and most negative aspects.

\section{Use Case}

This study uses the urban spatial plan of Faisalabad city, which is called Faisalabad Peri-Urban Structure Plan 2035 (FPUSP) to test the EasyUAZ tool. Faisalabad is the third-largest city of Pakistan, with more than 3.2 million population [81] and the built-up area of more than 260 square kilometres. The FPUSP was developed in 2015 by the City District Government under the Punjab Cities Governance Improvement Project (PCGIP) with the support of consultants, including the Urban Unit under the financial assistance of the World Bank. The Faisalabad Peri-Urban Structure Plan (FPUSP) 2035 is the first and the only approved spatial plan in the country which has witnessed the documented application of a GIS-based land suitability analysis $[82,83]$. The final report of the plan contains most of the essential details and underlying assumptions behind the plan-making. Hence, it provides a relevant case study to evaluate and compare the results. For this research, a subset of the spatial data and plan preparation assumptions from FPUSP has been used. Table 1 presents the list of data layers taken from FPUSP along with the layer type and the key attributes that need to be processed by the EasyUAZ tool in the data preparation for further processing in the Online WhatIf? PSS. In contrast, Table 2 presents the list of factor layers and associated classes that have been used in FPUSP preparation and contains all the data going into the EasyUAZ tool. These factor layers were required to be developed from the data layers (given in Table 2) using various geoprocessing tools available in the tool kits of each software. The factor data obtained from each generated layer are then attached to each parcel polygon, and finally, a polygonal file (UAZ) is generated as an output which could qualify as an input to the Online WhatIf? PSS. In Table 3, 'Classes' refers to the number of spatial buffer rings along with a distance of each ring. For instance, ' 5 classes of $500 \mathrm{~m}$ ' denotes that five buffer rings have to be prepared with $500 \mathrm{~m}$ width for each buffer ring. Furthermore, the 'Factor Type' refers to the classification of planning factors based on their nature, adapted from Hussnain et al. [28]. The 'proximity factors' refer to the factor layers which are based on the spatial distance or proximity to particular land use. Meanwhile, 'policy factors' refers to the factors based on the data sets derived from the policy documents.

Table 2. Data layers used by the participants.

\begin{tabular}{|c|c|c|c|c|}
\hline Sr. & Layers * & Type & Key Attributes (Other than Spatial) & Relevant Module ** \\
\hline 1 & Land parcels & Polygon & Land uses & $\mathrm{S}$ \\
\hline 2 & Water bodies & Polygon & River bed (Active, inactive) & $S$ \\
\hline 3 & Dumping Site & Polygon & Location & $\mathrm{S}$ \\
\hline 4 & Housing schemes & Polygons & Approval status, number of plots, area & S \\
\hline 5 & Government-owned land & Polygon & Area & $\mathrm{S}$ \\
\hline 6 & Health facilities & Polygon & Name, type, coverage & $\mathrm{S}$ \\
\hline 7 & Industries & Polygon & Name, type, size & $\mathrm{S}$ \\
\hline 8 & Education institutions & Points & Type, class & $\mathrm{S}$ \\
\hline 9 & Community facilities & Points & Name, type, area & $S$ \\
\hline 10 & Road network & Lines & Existing road, names, road class & S \\
\hline 11 & Water supply network & Lines & Service area existing \& future & $\mathrm{S}, \mathrm{A}$ \\
\hline 12 & Sewerage network & Lines & Service area existing \& future & $\mathrm{S}, \mathrm{A}$ \\
\hline 13 & Electric power network & Lines & Service area existing \& future & $\mathrm{S}, \mathrm{A}$ \\
\hline 14 & Priority areas & Polygons & Future development priority & A \\
\hline 15 & Planned land uses & Polygons & Pre-determined allocations & A, D \\
\hline 16 & Demography & Polygons & Demographic information & $\mathrm{D}, \mathrm{A}$ \\
\hline
\end{tabular}

* all layers were in shapefile format in the projected coordinate system. ${ }^{* *} \mathrm{~S}=$ Suitability, $\mathrm{D}=$ Demand, $\mathrm{A}=\mathrm{Allocation}$ :

The three modules in the Online WhatIf? 
Table 3. List of factor layers and associated classes to be generated.

\begin{tabular}{llll}
\hline Sr.No. & Factor Name & Classes & Factor Type \\
\hline 1 & Distance from Airport & 5 classes of $500 \mathrm{~m}$ & Proximity \\
2 & Distance from existing City Limits & 5 classes of $500 \mathrm{~m}$ & Proximity \\
3 & Distance from Community Facilities & 5 classes of $500 \mathrm{~m}$ & Proximity \\
4 & Distance from Employment centres & 5 classes of $500 \mathrm{~m}$ & Proximity \\
5 & Distance from Industrial Areas & 5 classes of $500 \mathrm{~m}$ & Proximity \\
7 & Distance from Irrigation Network & 5 classes of $500 \mathrm{~m}$ & Proximity \\
8 & Distance from Landfill Sites & 5 classes of $500 \mathrm{~m}$ & Proximity \\
9 & Distance from commercial centres & 5 classes of $500 \mathrm{~m}$ & Proximity \\
10 & Protected Sites & 2 classes & Proximity \\
11 & Distance from Public Water and Sewer Services & 5 classes of $500 \mathrm{~m}$ & Proximity \\
12 & Distance from Residential Areas & 5 classes of $500 \mathrm{~m}$ & Proximity \\
13 & Priority areas for future development & 3 classes & Policy \\
14 & Distance from Transport Network & 5 classes of $500 \mathrm{~m}$ & Proximity \\
15 & Flood Prone Area & 3 classes of $2 \mathrm{~km}$ & Proximity \\
16 & Land Agriculture Value & 2 classes & Policy \\
\hline
\end{tabular}

\section{Results and Discussion}

In the current working modality, the UAZ file for the Online WhatIf? is typically created using offline desktop-based applications. The Online WhatIf? user documentation [72] has enlisted the six steps, which can be repeated by $n$ times (where $n$ denotes the number of layers/factors) to produce the final form of UAZ. These steps include (a) Combining GIS layers; (b) Removing multi-part Features; (c) Removing slivers; (d) Creating/correcting topology; (e) Deleting unnecessary data fields, and (f) Creating the UAZ shapefile. Generally, when the Online WhatIf? is implemented in real-world projects, the number of factor layers exceeds ten and these can be updated through several iterations as the stakeholder refine the key input for the scenario planning process. Hence the data pre-processing in preparing the UAZ process can be time-consuming, and arduous reported by Russo et. and decrease the useability of the OWI PSS [28]. The problem is exacerbated in developing countries like Pakistan, where national spatial data infrastructures (NSDIs) are yet not in place. In the absence of standardised datasets, processing of datasets to generate desired results becomes challenging.

\subsection{Development of EasyUAZ}

Considering the dynamics of user experience with user interface (UX-UI) and TTF, the EasyUAZ tool has been designed to offer a structured workflow process where users are guided through the procedural steps in a sequence employing a user-friendly visual interface. The Online WhatIf? expects the input UAZ file to qualify specific geometric characteristics and attributes completion checks. The EasyUAZ has been designed to ensure that those conditions are met. To support the real-life projects which require the processing of a long list of factors and data files, the EasyUAZ has been designed to guide the user for considering the factors under various possible categories, such as proximity factors, policy factors, growth control or composite factors.

The EasyUAZ workflow tool has been implemented as a QGIS plugin, considering the stability, growth in user base and worldwide adaptability of OSGeo ecosystem [84,85]. The technology stack has been presented in Figure 5. 
QGIS 3.8, it is long term stable release for $3 . \mathrm{x}$ series. (https://qgis.org/en/site/forusers/d ownload.html )

Python 3.7 and the environment variables, python is a high level programming language that is used for QGIS plugin development. (https://www.python.org/downloads/)

Pycharm community edition, used as the integrated development environment (https://www.jetbrains.com/pycharm/ download/\#section=windows )

PyQT5 for rendering the GUI of EasyUAZ

PyQGIS which serves as QGIS python environment. Matplotlib for creating charts

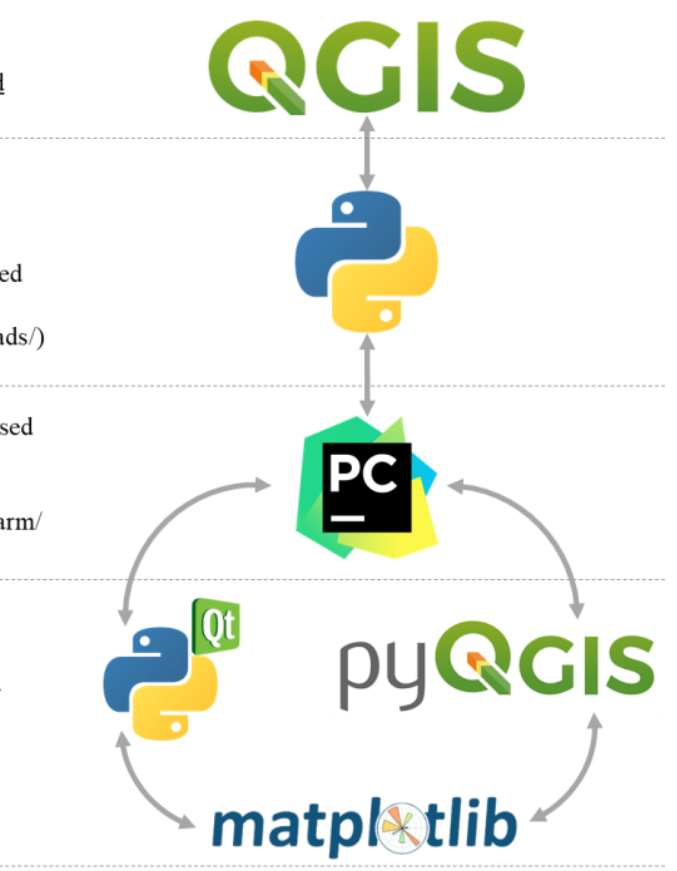

Figure 5. Technology stock behind EasyUAZ.

This section provides the visual and functional details on the EasyUAZ, which can be accessed using the QGIS Desktop, as it has been built as a stand-alone plugin (See Figure 6).

What is UAZ? UAZs are GIS-generated polygons which are homogeneous in all respects considered in the OWI model for land suitability and landuse allocation analysis. For example, all locations within a UAZ have the same slope, are located in the same municipality, have the same environmental value, are within the same distance of an existing or proposed highway, and so on. UAZs are created by using a GIS to combine all of the relevant layers of information to be used in an OWI project. The map layers can contain information on natural conditions (e.g., slopes, soils, and scenic vistas), existing and proposed infrastructure (e.g., the proximity to major roads and the availability of sewer and water service), and land use controls such as zoning districts and planned land uses. OWI combines these layers to produce UAZs which contain information from each of the constituent layers, i.e., each UAZ contains information on the slope, the availability of sewer and water service, planned land use, and so on for the locations inside it.

About the UAZ Tool: This tool has been developed to automate the UAZ preparation process. It checks if the polygonal layer file contains all the necessary columns needed by the OWI model and if the file is geometrically correct. Furthermore, it allows user to assign attributes to the file based on polygons spatial placement from other urban attributes. In a nutshell, it provides a one-stop solution to make the UAZ file ready for OWI.

Financial Support: This plugin has been developed with the financial support of HEC Pakistan under the National Research Program for Universities (NRPU)

Updates: To see the latest updates or read more about the Tool, please visit https:/github.com/junaidgis/owi-uaz

Developers: Hussain M.Q; Jabbar. J.A; Email: drwaheed@nit.nust.edu.pk

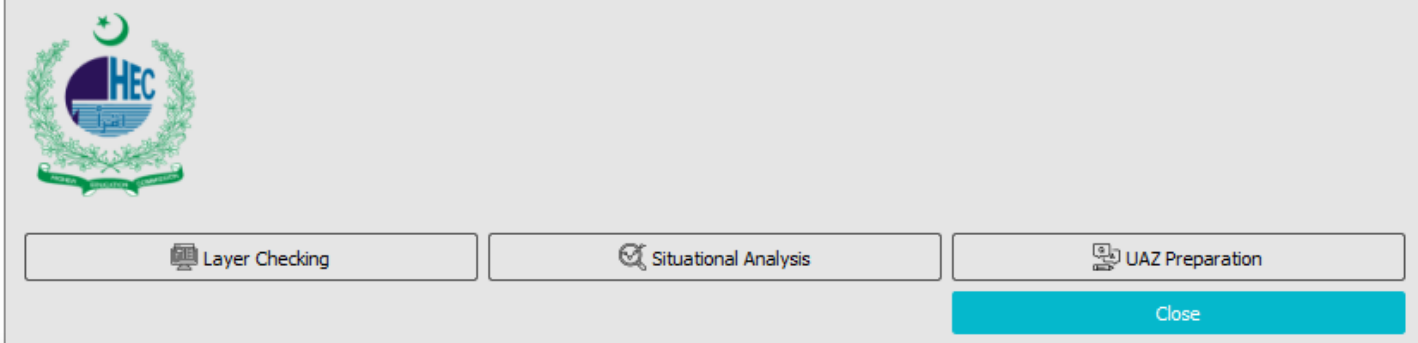

Figure 6. Uniform Analysis Zones (UAZ) Preparation Plugin; landing screen.

The developed plugin demonstrates the following functional strengths: 


\subsubsection{Layer Checking Module}

The layer checking module allows the user to check multiple conditions on the base parcels/polygons file. These conditions are required to be satisfied for feeding data into the Online WhatIf?. The conditions are pre-populated, and the user has the option to check or uncheck specific conditions based on the requirement. Figure 7 shows the interface of the layer checking module. A tick mark sign appears for every satisfied condition, and in case of unsatisfied conditions and cross appears with further instructions for the user-populated in the status column.

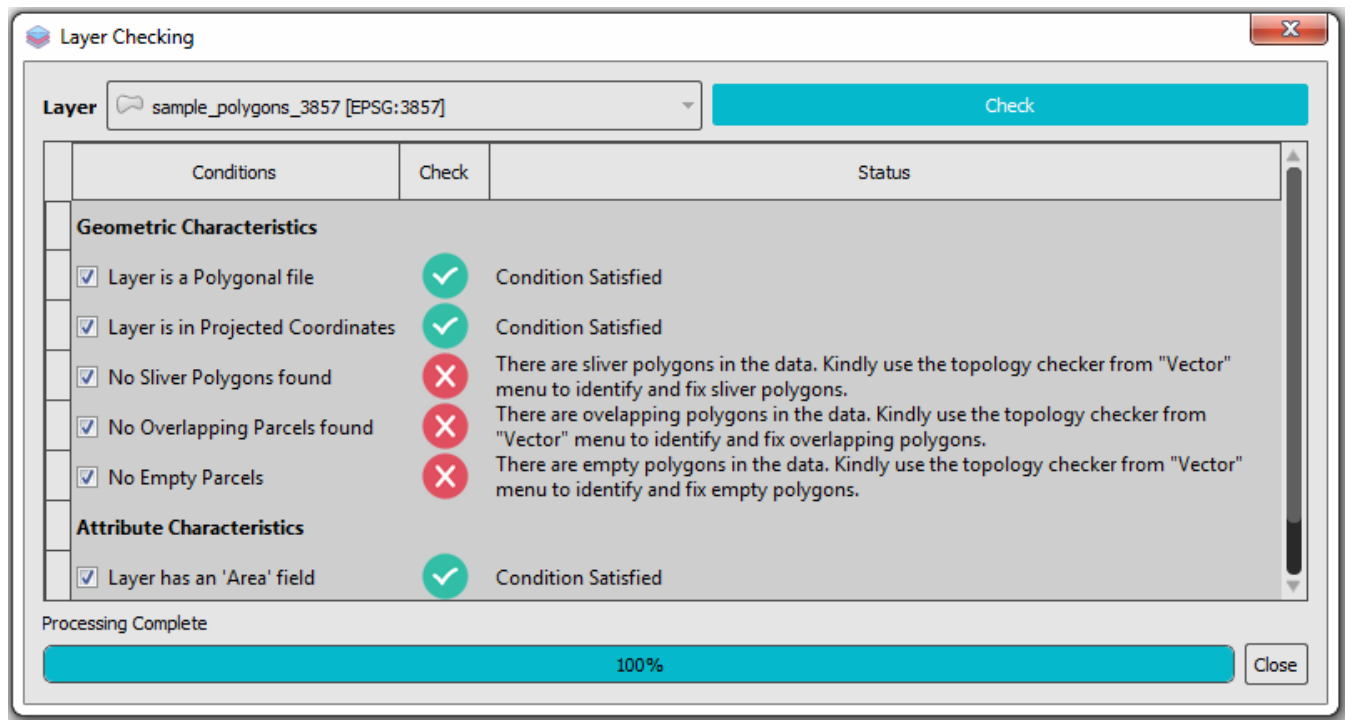

Figure 7. Layer checking function.

\subsubsection{Situational Analysis Module}

Situation Analysis allows the user to perform statistical analysis on the data. The user has to select the relevant data layer based on which the attributes are available in a drop-down list so that the user can select the classification attribute. It allows the user to view area classification based on values or percentages of the values. Users can also export the pie chart in PNG format for use in other reports (see Figure 8).

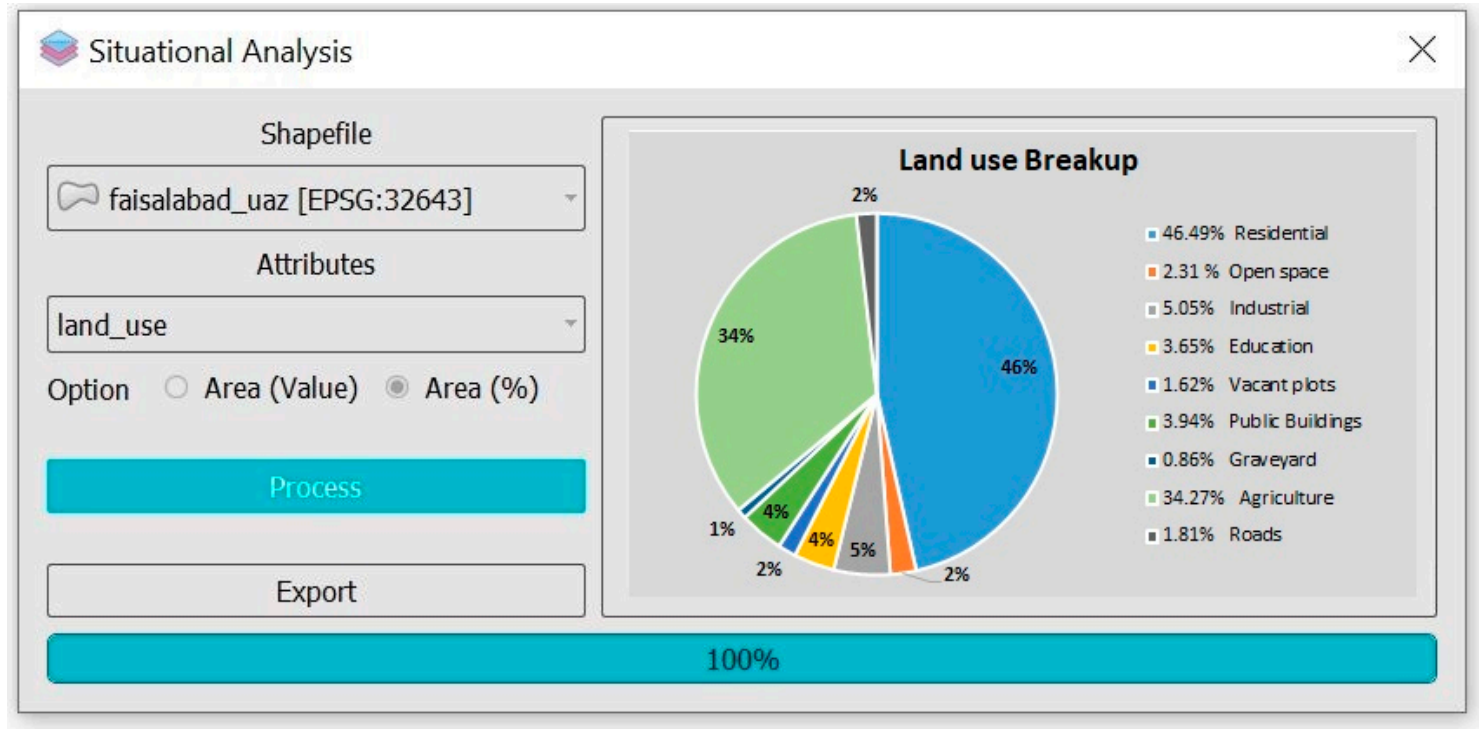

Figure 8. Descriptive statistical summary of layer attributes. 


\subsubsection{UAZ Preparation}

UAZ Preparation module allows the user to process the parcels layer and include values for multiple factors that are to be used in the Online WhatIf? analysis. There are three categories of factors:

Proximity Factors: This tab provides the user with 15 pre-populated proximity factors with the option to check, uncheck, and add new factors as per requirement. The user has to select the relevant data shapefile for every factor and enter the buffer interval value. No of Intervals refers to the buffer rings that are required for making proximity classes. The Result Field column is to be populated with the name of the field required in the output file. Once all the required values are added, and the Process button is clicked, the EasyUAZ tool now performs the spatial analysis between the base layer and factor layers to add factor attributes in the base layer and populate them with the respective values (see Figure 9).

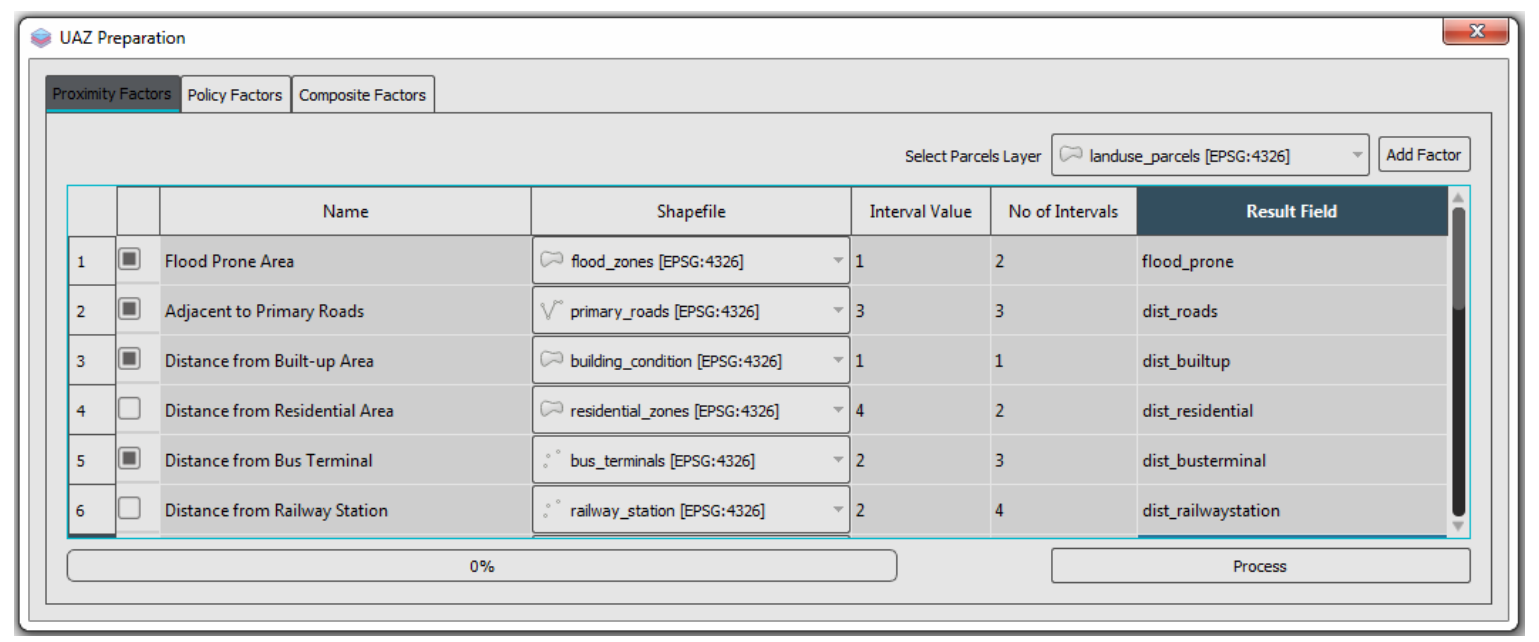

Figure 9. Interface showing the listing of opportunity and constraint factors.

Policy Factors and Composite Factors: These tabs provide the user with two pre-populated factors, each with the option to check, uncheck, and add new factors as per requirement. Here, the user has to select relevant data shapefile and then the respective attribute for the Source Field column based on which the intersection operation is performed, and values are then populated in the result fields.

\subsection{Evaluation of the Workflow Tool}

\subsubsection{Technical Evaluation of the Workflow Tool}

The analysis of the experiment observations reveals that users have taken $297 \mathrm{~min}$ on average when they prepare a UAZ with ArcGIS, which increases to 320 min when the UAZ preparation is done through QGIS. However, in the case of the EasyUAZ, the average time turned out to be $217 \mathrm{~min}$, which is 30\% less than the ArcGIS and 35\% lesser than QGIS generic tools (see Figure 10).

Table 4 represents the interquartile range of the experimental results, which are graphically represented by a box and whisker plot in Figure 11. The analysis reveals that the minimum recorded time for UAZ preparation with the EasyUAZ has been $187 \mathrm{~min}$, which is considerably less than QGIS Desktop (285 min) and ArcGIS (269 min). This time efficiency is triangulated from the first quartile distribution, which is measured as 196, 299, and $285 \mathrm{~min}$ for the EasyUAZ, QGIS, and ArcGIS, respectively. In terms of range, the EasyUAZ reflects the most compact form of all three processes with a value of 52 , followed by ArcGIS with a more significant range spread of 81 . At the same time, QGIS has the most extensive range of 107 , which shows that users have a higher diversity of completion time with QGIS. In the case of EasyUAZ, most of the users were able to complete the task in a closer time range. 
Time (minutes) taken by participants to prepare the UAZ file with three approaches

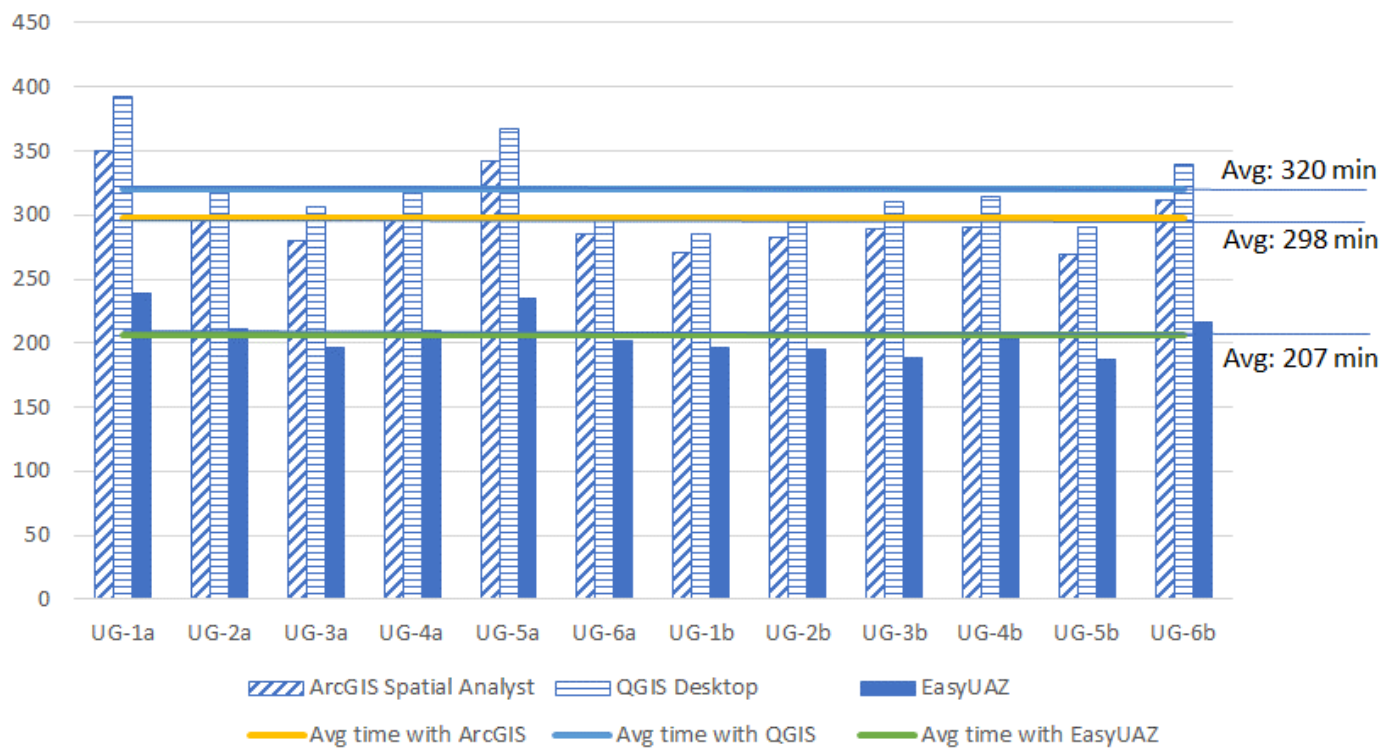

Figure 10. Distribution of UAZ preparation task completion under different workflows.

Table 4. The statistical distribution of task completion time (in minutes).

\begin{tabular}{cccc}
\hline & ArcGIS Spatial Analyst & QGIS Desktop & EasyUAZ \\
\hline Min & 269 & 285 & 187 \\
Q1 & 282 & 298 & 195 \\
Median & 290 & 312 & 205 \\
Q3 & 302 & 325 & 212 \\
Max & 350 & 392 & 239 \\
Mean & 297 & 320 & 207 \\
Range & 81 & 107 & 52 \\
\hline
\end{tabular}

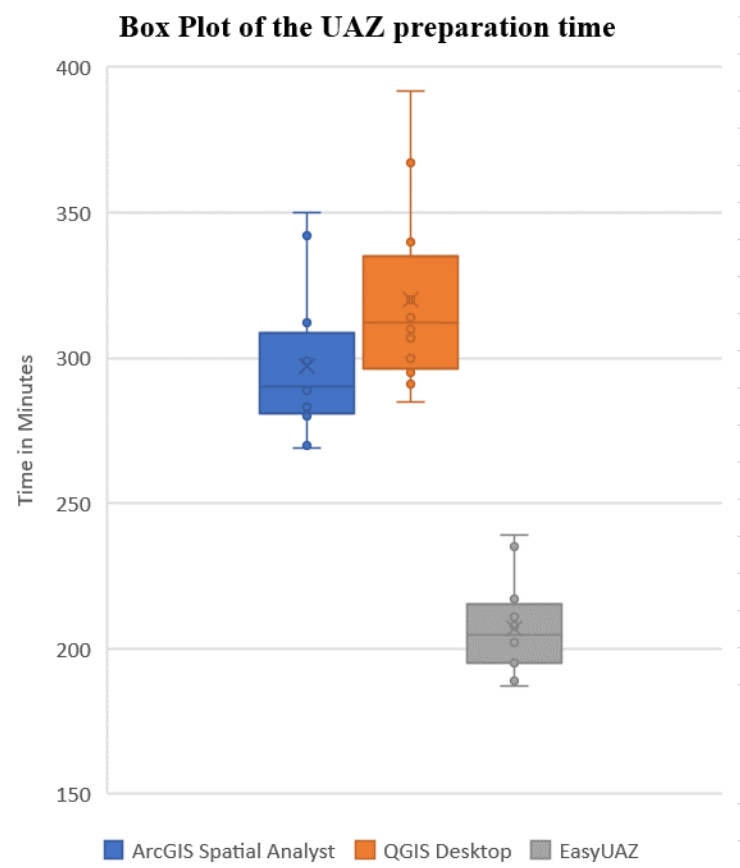

Figure 11. Box plot of UAZ preparation time (minutes). 
Another useful insight earned with the experiment is to explore how the differences in the time needed to complete the task with EasyUAZ vs. ArcGIS/QGIS is affected by processing time (only), which varies in ArcGIS vs. QGIS, and due to the case of possible more complex workflow in the manual approach. This is interesting to understand that the gross time differences are primarily due to the 'user action' rather than the 'processing time'. Some comparative studies have [86-89] compared the functionalities and geo-processing time requirement of both of the applications while an endless comparison debate can be seen on the Q\&A websites such as StackOverflow and StackExchange. It has been observed that for the given geoprocessing tasks, there exists a very marginal difference between the processing time with QGIS vs. ArcGIS, which has been recorded as $175 \mathrm{~min}$ vs. $165 \mathrm{~min}$, respectively (see Figure 12). The EasyUAZ primarily improves the 'user action time' by reducing it by $67 \%$ when compared with QGIS and $64 \%$ in the case of ArcGIS. Furthermore, a reduction of $10 \%$ time has also been noticed against QGIS.

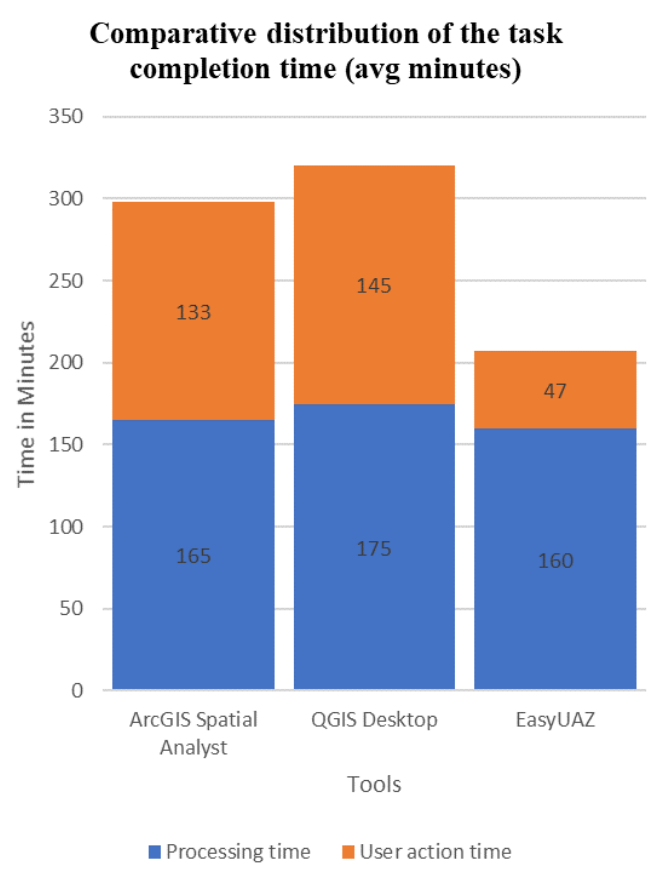

Figure 12. Comparative distribution of the task completion time.

\subsubsection{User Experience (Focused Group Discussion)}

While discussing the ease of using the workflow and the improvements in the overall experience, the participants commented on their preference for using the EasyUAZ. "Although the ArcGIS toolbox is very powerful, we need to search for the relevant commands while in case of EasyUAZ, those processes have been pre-selected, making it very handy," narrated one participant. Similarly, others shared that during the tasks' performance with the generic GIS tools (ArcGIS and QGIS), they had to spend considerable time figuring out the right flow of geo-processes. On the other hand, the EasyUAZ tool presented a customised and structured approach where the desired commands were pre-embedded in the tool, along with their sequencing, to support urban research workflow required to create the UAZ file. Another participant commented, "EasyUAZ will be particularly useful for users having lesser experience in GIS workflows including buffering, shapefile editing, spatial joins etc". One participant commented that "In the case of ArcGIS and QGIS, we remained more focused on finding the GIS commands and geoprocessing tools than thinking about the planning problem at hand. While the EasyUAZ took that burden off, we were more focused onto the placement of planning factors and their categorisation. For example, while using EasyUAZ, I did not have to worry about what GIS processes are going at the backend; rather, I enjoyed categorising opportunity and constraint layers. I realised that I had some differences in how those factors were arranged, and I was able to rearrange them as per 
my choice". Most of the participants appreciated that EasyUAZ has been based on open source tools and hoped that this would allow a broader audience to contribute in the future and a great uptake due to both EasyUAZ and OWI being freely available.

On the other hand, while discussing the negative aspects, one participant noted that the EasyUAZ tool was not as stable as the generic GIS tools-" at the final stage of adding attributes to the UAZ file, the QGIS halted and was not responding for a long time. This delay crashed the EasyUAZ. It was shocking. However, I was relieved to know that the outputs of all the processes completed until that point were saved, and I did not have to redo all of the work". Another participant commented that that "although the EasyUAZ can detect topology errors, the fixing of topology has to be done outside the tool. It would be great if that can also be integrated within the workflow". The current unavailability of PyQGIS core APIs for topology checker is a barrier to incorporating this functionality in the EasyUAZ at the moment.

Another exciting dimension is exploring the extent to which the automation of the workflow, which indeed proved to increase the focus on spatial thinking rather than geo-processing, would have been affected to the black box effect, particularly for the new users. Since the inputs and output of the EasyUAZ are well known and well expected to the users; the automation does not create a sense of the usual software-related black box effect. In the traditional data preparation process for Online WhatIf?, the users have to trust the GIS tool (ArcGIS or QGIS) for the geoprocessing tasks, and that same level of the black-box syndrome would prevail for EasyUAZ as well. This tool does not alter or modify any of the geoprocessing tasks in their primary working; instead, it helps the users arrange their planning-factors data layers and run the necessary processing tasks more systematically so that the final output could match with the Online WhatIf? Input needs.

\subsubsection{Other Use Cases}

The participants were able to identify additional use cases for the EasyUAZ tool. Although the tool was initially designed to support the Online WhatIf? workflow [27], participants noted its value in assisting in data preparation for other spatial multi-criteria decision-making processes. In its current form, it can be used to calculate and add geometry fields (i.e., area) to the projected files.

Furthermore, it offers the summary calculations and charting on any attribute field, which can provide useful descriptive statistics when commencing new exploratory planning studies. The results of the factor calculations and classifications can be saved as the intermediary outputs. Those can be used for weighted overlay studies in other generic GIS tools (e.g., ArcGIS model builder) or other spatial MCE planning tools $[90,91]$ other than the Online WhatIf?.

\section{Conclusions}

For the last ten years, there has a significant increase in the development and availability of planning support systems. However, the adoption has been slow due to various demand and supply factors. On the supply side, data hungriness and extensive data preparation requirements have been identified as a significant challenge to wider adoption $[4,6,7]$. The existing range of available PSS tools used in research and practice are data-intensive and require significant effort in conducting data pre-processing, cleaning, and loading, which remains a barrier to their wider adoption. Mostly the developers tend to focus more on PSS development to solve complex planning problems and give less attention to the data preparation workflow requires to support such data-intensive tools. As a result, many PSS are not well used as they require deep expertise in GIS and also there is a considerable investment in the time for configuring urban models and scenario planning tools. The development of the EasyUAZ tool presented in this paper endeavours to address these important issues to support the more rapid application of data-driven scenario planning tools to ensure they provide timely advice to planners and policy-makers [73].

This research presents a data processing workflow tool, the EasyUAZ, designed to support the Online WhatIf? planning support system. By applying the task-technology-fit (TTF) on the standard 
practice workflow of the Online WhatIf? to generate UAZ, requirements for the new pre-processing tool were documented, and the tool was developed as a QGIS plugin The comparative evaluation of the tool against a proprietary tool- based workflow (i.e., ArcMap) as well as an open-sourced tool based workflow (i.e., QGIS) reveals that the new tool can reduce the UAZ preparation time by $30 \%-35 \%$. The other identified advantages include the ease of use, the opportunity for the user of PSS to focus more on the scenario planning approach rather than geospatial processing and file handling, and a shorter learning curve for basic GIS users. Its availability as an open-source tool will have an increased potential for future development and contribution by other users. Considering the large user base of the Online WhatIf? planning support system, the EasyUAZ tool will be beneficial to the existing and future users and will help improve the further adaptation of the PSS and ultimately other spatial MCE planning tool identified such as ENVISION [91]. Furthermore, this research has identified the need for further research and development into the simplification of complex urban models through reducing data processing time and ensure such models and planning support systems remain useable and relevant.

Author Contributions: Conceptualization, Muhammad Qadeer ul Hussnain, Abdul Waheed, Junaid Abdul Jabbar and Christopher James Pettit; data curation, Muhammad Qadeer ul Hussnain and Khydija Wakil; formal analysis, Muhammad Qadeer ul Hussnain and Khydija Wakil; funding acquisition, Ali Tahir; Investigation, Ali Tahir; methodology, Muhammad Qadeer ul Hussnain, Junaid Abdul Jabbar and Christopher James Pettit; project administration, Abdul Waheed and Ali Tahir; resources, Abdul Waheed and Christopher James Pettit; software, Khydija Wakil and Junaid Abdul Jabbar; supervision, Christopher James Pettit; validation, Junaid Abdul Jabbar; visualization, Muhammad Qadeer ul Hussnain, Abdul Waheed and Junaid Abdul Jabbar; writing —original draft, Muhammad Qadeer ul Hussnain, Khydija Wakil and Christopher James Pettit; writing-review \& editing, Christopher James Pettit and Ali Tahir. All authors have read and agreed to the published version of the manuscript.

Funding: This research was funded by the HIGHER EDUCATION COMMISSION (HEC), PAKISTAN under grant no: NRPU-6007, and The APC was funded by NATIONAL UNIVERSITY OF SCIENCES AND TECHNOLOGY (NUST), PAKISTAN.

Acknowledgments: We would like to acknowledge the three anonymous reviewers who contributed to the quality of the paper by raising important points related to the black-box effect and time saving attributions.

Conflicts of Interest: The authors declare no conflict of interest

\section{References}

1. Russo, P.; Costabile, M.F.; Lanzilotti, R.; Pettit, C.J. Planning Support Systems and Smart Cities; Springer: New York, NY, USA, 2015; pp. 337-353. [CrossRef]

2. Pettit, C.; Bakelmun, A.; Lieske, S.N.; Glackin, S.; Hargroves, K.; Thomson, G.; Shearer, H.; Dia, H.; Newman, P. Planning support systems for smart cities. City Cult. Soc. 2018, 12, 13-24. [CrossRef]

3. Vonk, G.; Geertman, S. Improving the Adoption and Use of Planning Support Systems in Practice. J. Appl. Spat. Anal. Policy 2008, 1, 153-173. [CrossRef]

4. Russo, P.; Lanzilotti, R.; Costabile, M.F.; Pettit, C.J. Adoption and Use of Software in Land Use Planning Practice: A Multiple-Country Study. Int. J. Hum. Comput. Interact. 2017, 34, 57-72. [CrossRef]

5. Holway, J.; Gabbe, C.; Hebbert, F.; Lally, J.; Mathews, R.; Quay, R. Opening Access to Scenario Planning Tools, Cambridge, 2012. Available online: https://www.lincolninst.edu/pubs/2027_Opening-Access-to-ScenarioPlanning-Tools (accessed on 25 November 2020).

6. Vonk, G.; Geertman, S.; Schot, P. Bottlenecks blocking widespread usage of planning support systems. Environ. Plan. A 2005, 37, 909-924. [CrossRef]

7. Hussnain, M.Q.; Waheed, A.; Anjum, G.A.; Naeem, M.A.; Hussain, E.; Wakil, K.; Pettit, C.J. A framework to bridge digital planning tools' utilisation gap in peri-urban spatial planning; lessons from Pakistan. Comput. Environ. Urban Syst. 2020, 80, 101451. [CrossRef]

8. Waddell, P. UrbanSim: Modeling Urban Development for Land Use, Transportation, and Environmental Planning. J. Am. Plan. Assoc. 2002, 68, 297-314. [CrossRef]

9. Kim, D.; Batty, M. Calibrating Cellular Automata Models for Simulating Urban Growth: Comparative Analysis of SLEUTH and Metronamica. UCL Work. Pap. Ser. 2011, 176, 38. Available online: https://www.ucl.ac.uk/ bartlett/casa/sites/bartlett/files/migrated-files/paper176.pdf (accessed on 25 November 2019). 
10. Clarke, K.C. A Decade of Cellular Urban Modeling with SLEUTH: Unresolved Issues and Problems, Ch. 3 in Planning Support Systems for Cities and Regions. 2008. Available online: http://bbs.geog.ucsb.edu (accessed on 28 April 2020).

11. Boulangé, C.; Pettit, C.; Giles-Corti, B. The Walkability Planning Support System: An Evidence-Based Tool to Design Healthy Communities. In Planning Support Science for Smarter Urban Futures; Geertman, S., Allan, A., Pettit, C., Stillwell, J., Eds.; Springer International Publishing: Cham, Switzerland, 2017; pp. 153-165.

12. Pelzer, P.; Geertman, S.; van der Heijden, R. A comparison of the perceived added value of PSS applications in group settings. Comput. Environ. Urban Syst. 2016, 56, 25-35. [CrossRef]

13. Brömmelstroet, M.; Pelzer, P.; Klerkx, R.; Schaminée, S. Do Planning Support Systems Improve Planning? Testing the claim in a controlled experiment. In Planning Support Systems for Sustainable Urban Development; Springer: New York, NY, USA, 2013; pp. 1-21.

14. Pelzer, P.; Arciniegas, G.; Geertman, S.; Lenferink, S. Planning Support Systems and Task-Technology Fit: A Comparative Case Study. Appl. Spat. Anal. Policy 2015, 8, 155-175. [CrossRef]

15. Pettit, C.J.; Wyatt, R. A Planning Support System Toolkit Approach for Formulating and Evaluating Land-use Change Scenarios. In Planning Support Systems Best Practice and New Methods; Geertman, S., Stillwell, J., Eds.; Springer: Dordrecht, The Netherlands, 2009; pp. 137-157.

16. Waddell, P. Integrated land use and transportation planning and modelling: Addressing challenges in research and practice. Transp. Rev. 2011, 31, 209-229. [CrossRef]

17. Rainis, R.; Shamsudin, K.; Jaafar, M.N.; Shah, H.H. Development of the Klang Valley Regional Planning Support System. In Planning Support Systems in Practice; Geertman, S., Stillwell, J., Eds.; Springer: Berlin/Heidelberg, Germany, 2003; pp. 409-433.

18. Schnaars, S.P. How to develop and use scenarios. Long Range Plan. 1987, 20, 105-114. [CrossRef]

19. Godet, M. How to be rigorous with scenario planning. Foresight 2000, 2, 5-9. [CrossRef]

20. Goodspeed, R. Scenario Planning for Cities and Regions Managing and Envisioning Uncertain Futures; Lincoln Institute of Land Policy: Cambridge, MA, USA, 2020.

21. Pettit, C.J.; Klosterman, R.E.; Delaney, P.; Whitehead, A.L.; Kujala, H.; Bromage, A.; Nino-Ruiz, M. The Online What if? Planning Support System; Springer: Berlin/Heidelberg, Germany, 2013; Volume 195, pp. 107-125. [CrossRef]

22. Pettit, C.; Klosterman, R.E.; Delaney, P.; Whitehead, A.; Kujala, H.; Bromage, A.; Nino-Ruiz, M. The Online What if? Planning Support System: A Land Suitability Application in Western Australia. Appl. Spat. Anal. Policy 2015, 8, 93-112. [CrossRef]

23. Klosterman, R.E. The What if? Collaborative planning support system. Environ. Plan. B 1999, 26, $393-408$. [CrossRef]

24. Brail, R.K.; Klosterman, R.E. Planning Support Systems: Integrating Geographic Information Systems, Models, and Visualisation Tools; ESRI Inc.: New York, NY, USA, 2001.

25. Pettit, C.; Keysers, J.; Bishop, I.; Klosterman, R. Applying the What If? Planning Support System for Better Understanding Urban Fringe Growth. In Landscape Analysis and Visualisation: Spatial Models for Natural Resource Management and Planning; Pettit, C., Cartwright, W., Bishop, I., Lowell, K., Pullar, D., Duncan, D., Eds.; Springer: Berlin/Heidelberg, Germany, 2008; pp. 435-454.

26. Hussnain, M.Q.; Waheed, A.; Wakil, K.; Tahir, A.; Pettit, C.; Pelizaro, C.; Jabbar, J.A. A Planning Support System to Aid Spatial Planning in Pakistan. In Computers in Urban Planning and Urban Management (CUPUM2017); University of South Australia: Adelaide, Australia, 2017.

27. Pettit, C.; Biermann, S.; Pelizaro, C.; Bakelmun, A. A Data-Driven Approach to Exploring Future Land Use and Transport Scenarios: The Online What If? Tool. J. Urban Technol. 2020, 732, 20-44. [CrossRef]

28. Hussnain, M.Q.; Waheed, A.; Anjum, G.A.; Naeem, M.A.; Wakil, K.; Tahir, A.; Pettit, C.; Hussain, E. Application of the Online WhatIf? Planning Support System in Peri-urban Spatial Planning; Case study of Muzaffargarh, Pakistan. In Proceedings of the 24th International Conference on Urban Planning and Regional Development in the Information Society, Karlsruhe, Germany, 2-4 April 2019; pp. 77-87.

29. Russo, P.; Lanzilotti, R.; Costabile, M.F.; Pettit, C.J. Towards satisfying practitioners in using Planning Support Systems. Comput. Environ. Urban Syst. 2018, 67, 9-20. [CrossRef]

30. Pettit, C.; Shyy, T.-K.; Stimson, R. An On-line Planning Support System to Evaluate Urban and Regional Planning Scenarios. In Planning Support Systems in Practice. Advances in Spatial Science; Geertman, S., Stillwell, J., Eds.; Springer: Berlin/Heidelberg, Germany, 2003. 
31. Bishop, I.; Pettit, C.J.; Van, B.D.; Lynch, J. Visualising What If? Generated Land Use Planning Scenarios. Available online: http://www.dupad.hku.hk/cupumhk/ (accessed on 25 November 2020).

32. Pettit, C.; Pullar, D. A way forward for land-use planning to achieve policy goals by using spatial modelling scenarios. Environ. Plan. B Plan. Des. 2004, 31, 213-233. [CrossRef]

33. Guhathakurta, S. Urban modeling and contemporary planning theory: Is there a common ground? J. Plan. Educ. Res. 1999, 18, 281-292. [CrossRef]

34. Pelzer, P.; Geertman, S.; van der Heijden, R.; Rouwette, E. The added value of Planning Support Systems: A practitioner's perspective. Comput. Environ. Urban Syst. 2014, 48, 16-27. [CrossRef]

35. Pelzer, P.; Geertman, S.; van der Heijden, R. Knowledge in communicative planning practice: A different perspective for planning support systems. Environ. Plan. B Plan. Des. 2015, 42, 638-651. [CrossRef]

36. Ratti, C.; Claudel, M. The City of Tomorrow: Sensors, Networks, Hackers, and the Future of Urban Life; Yale University Press: London, UK, 2016.

37. Townsend, A.M. Smart Cities: Big Data, Civic Hackers, and the Quest for a New Utopia; WW Norton \& Company: New York, NY, USA, 2013.

38. Hamilton, A.; Wang, H.; Tanyer, A.M.; Arayici, Y.; Zhang, X.; Song, Y. Urban information model for city planning. J. Inf. Technol. Constr. 2005, 10, 55-67.

39. Thakuriah, P.; Tilahun, N.Y.; Zellner, M. Big data and urban informatics: Innovations and challenges to urban planning and knowledge discovery. In Springer Geography; Springer: Berlin/Heidelberg, Germany, 2017; pp. 11-45.

40. Ahmed, N.S. Big Data and Urban Planning in Pakistan: A Case Study of The Urban Unit; York University: Toronto, ON, Canada, 2018.

41. Stohr, E.A.; Zhao, J.L. Workflow Automation: Overview and Research Issues. Inf. Syst. Front. 2001, 3, 281-296. [CrossRef]

42. Verborgh, R.; de Wilde, M. Using OpenRefine; Packt Publishing Ltd.: Birmingham, UK, 2013.

43. Kusumasari, T.F. Fitria Data profiling for data quality improvement with OpenRefine. In Proceedings of the 2016 International Conference on Information Technology Systems and Innovation (ICITSI), Bandung, Indonesia, 24-27 October 2016; pp. 1-6. [CrossRef]

44. Groves, A. Beyond Excel: How to start cleaning data with OpenRefine. Multimed. Inf. Technol. 2016, 42, $18-22$.

45. Golubev, A.; Chechetkin, I.; Parygin, D.; Sokolov, A.; Shcherbakov, M. Geospatial Data Generation and Preprocessing Tools for Urban Computing System Development. Procedia Comput. Sci. 2016, 101, 217-226. [CrossRef]

46. GeoKettle. Available online: https://live.osgeo.org/archive/10.0/en/overview/geokettle_overview.html (accessed on 9 June 2020).

47. Data Visualisation | Microsoft Power BI. Available online: https://powerbi.microsoft.com/en-us/ (accessed on 9 June 2020).

48. ESRI. ArcGIS Workflow Manager | Enterprise Workflow Management System. Available online: https: //www.esri.com/en-us/arcgis/products/arcgis-workflow-manager/overview (accessed on 9 June 2020).

49. ESRI. What Is ModelBuilder? Available online: https://pro.arcgis.com/en/pro-app/help/analysis/ geoprocessing/modelbuilder/what-is-modelbuilder-.htm (accessed on 9 June 2020).

50. Olaya, V.; Cavallini, P. QGIS Processing Framework. Available online: https://docs.qgis.org/3.10/en/docs/ training_manual/processing/index.html (accessed on 7 June 2020).

51. Google. Google Earth Engine. Available online: https://earthengine.google.com/ (accessed on 9 June 2020).

52. SAFE, FME Workflow Management. 2020. Available online: https://www.safe.com/training/recorded/fmeworkflow-management/ (accessed on 27 May 2020).

53. SAFE, Safe Software |FME| Data Integration Platform. Available online: https://www.safe.com/ (accessed on 22 June 2020).

54. Hale Studio-Fast, Interactive Data Transformation. Available online: https://www.wetransform.to/products/ halestudio/ (accessed on 7 June 2020).

55. Waddell, P.; Janowicz, E.; Blanchard, S.; Maurer, S. UrbanCanvas: A collaborative platform for informed planning. In Handbook of Planning Support Science; Edward Elgar Publishing: Northampton, MA, USA, 2020.

56. UrbanCanvas-UrbanSim. Available online: https://urbansim.com/urbancanvas (accessed on 28 June 2020).

57. UrbanSim, Urban Data Science Toolkit. Available online: https://urbansim.com/udst (accessed on 16 June 2020). 
58. USGS. Project Gigalopolis. Available online: http://www.ncgia.ucsb.edu/projects/gig/Imp/imSetUp.htm (accessed on 28 June 2020).

59. Chaudhuri, G.; Clarke, K.C. The SLEUTH Land Use Change Model: A Review. Int. J. Environ. Resour. Res. 2013, 1, 88-104.

60. Hilferink, M.; Rietveld, P. LAND USE SCANNER: An integrated GIS based model for long term projections of land use in urban and rural areas. J. Geogr. Syst. 1999, 1, 155-177. [CrossRef]

61. Koomen, E.; Hilferink, M.; Beurden, J.B. Introducing land use scanner. In Land-Use Modelling in Planning Practice; Springer: Dordrecht, Germany, 2011; pp. 3-21.

62. Van Delden, H.; Escudero, J.C.; Uljee, I.; Engelen, G. METRONAMICA: A dynamic spatial land use model applied to Vitoria-Gasteiz. In Virtual Seminar of the MILES Project; Centro de Estudios Ambientales: Vitoria-Gasteiz, Spain, 2005; pp. 1-8.

63. De Silva, C.; Wimaladasa, J.; Munasinghe, J. Calibrating Metronamica Land Use Simulation Model for Colombo, Sri Lanka. Bhumi Plan. Res. J. 2015, 4, 1. [CrossRef]

64. Van Delden, H.; Vanhout, R. A Short Presentation of Metronamica. In Geomatic Approaches for Modeling Land Change Scenarios; Olmedo, M.T.C., Paegelow, M., Mas, J.-F., Escobar, F., Eds.; Springer International Publishing: Cham, Switzerland, 2018; pp. 511-519.

65. Li, Y.; Jiao, J. Comparative Analysis of Three Planning Support Software (PSS) Programs and Current Applications of Planning Support System in China. In Proceedings of the 13th International Conference on Computers in Urban Planning and Urban Management, Utrecht, Vietnam, 2-5 July 2013; pp. 1-20.

66. INDEX PlanBuilder User Notebook; Criterion Planners: Portland, OR, USA, 2007.

67. Kwartler, M.; Bernard, R.N. CommunityViz: An Integrated Planning Support System; Esri Press: New York, NY, USA, 2001; pp. 285-308.

68. Petzold, I.; Burghardt, D.; Bobzien, M. Workflow Management and Generalisation Services. In Proceedings of the 9th ICA Workshop on Generalization and Multiple Representation, Portland, OR, USA, 5 June 2006.

69. Jusuf, S.K.; Mousseau, B.; Godfroid, G.; Hui, V.S.J. Integrated modeling of CityGML and IFC for city/neighborhood development for urban microclimates analysis. Energy Procedia 2017, 122, 145-150. [CrossRef]

70. Pettit, C.J.; Barton, J.; Goldie, X.; Sinnott, R.; Stimson, R.; Kvan, T. The Australian Urban Intelligence Network Supporting Smart Cities. In Planning Support Systems and Smart Cities; Geertman, S., Goodspeed, J.F., Jr., Stillwell, J., Eds.; Springer International Publishing: Cham, Switzerland, 2015; pp. 243-259.

71. Sinnott, R.O.; Bayliss, C.; Bromage, A.; Galang, G.; Grazioli, G.; Greenwood, P.; Macaulay, A.; Morandini, L.; Nogoorani, G.; Nino-Ruiz, M.; et al. The Australia urban research gateway. Concurr. Comput. Pract. Exp. 2014, 27, 358-375. [CrossRef]

72. AURIN, Online WhatIf? User Guide. 2016. Available online: https://docs.aurin.org.au/what-if/online-whatifuser-guide/ (accessed on 25 November 2020).

73. Pettit, C.; Shi, Y.; Han, H.; Rittenbruch, M.; Foth, M.; Lieske, S.; Nouwelant, R.V.D.; Mitchell, P.; Leao, S.; Christensen, B.; et al. A new toolkit for land value analysis and scenario planning. Environ. Plan. B Urban Anal. City Sci. 2020. [CrossRef]

74. Pelzer, P. Usefulness of planning support systems: A conceptual framework and an empirical illustration. Transp. Res. Part A Policy Pract. 2017, 104, 84-95. [CrossRef]

75. Pettit, C.J.; Tanton, R.; Hunter, J. An online platform for conducting spatial-statistical analyses of national census data across Australia. Comput. Environ. Urban Syst. 2017, 63, 68-79. [CrossRef]

76. Barton, J.E.; Goldie, X.H.; Pettit, C.J. Introducing a usability framework to support urban information discovery and analytics. J. Spat. Sci. 2015, 60, 311-327. [CrossRef]

77. ESRI. ArcMap |Documentation. Available online: https://desktop.arcgis.com/en/arcmap/ (accessed on 8 May 2020).

78. QGIS, QGIS: A Free and Open Source Geographic Information System. 2019. Available online: https: //www.qgis.org/en/site/ (accessed on 22 May 2019).

79. Graziano, A.M.; Raulin, M.L. Research Methods: A process of Inquiry; HarperCollins College Publishers: New York, NY, USA, 1993.

80. Allen, M. The SAGE Encyclopedia of Communication Research Methods; SAGE: Thousand Oaks, CA, USA, 2017. [CrossRef] 
81. GoP. 6th Population and Housing Census 2017 (Provisional Results). Pakistan Bureau of Statistics: Islamabad, Pakistan, 2018. Available online: http://www.pbs.gov.pk/sites/default/files//Population_Census_ 2017_Results_0.pdf (accessed on 13 May 2019).

82. Hussnain, M.Q.U.; Waheed, A.; Wakil, K.; Pettit, C.; Hussain, E.; Naeem, M.A.; Anjum, G.A. Shaping up the Future Spatial Plans for Urban Areas in Pakistan. Sustainability 2020, 12, 4216. [CrossRef]

83. Afzal, M. Evaluation of Peri-Urban Structure Plan Practices in Punjab; University of Engineering and Technology: Lahore, Pakistan, 2016.

84. Coetzee, S.; Ivánová, I.; Mitasova, H.; Brovelli, M.A. Open geospatial software and data: A review of the current state and a perspective into the future. ISPRS Int. J. Geo-Inf. 2020, 9, 90. [CrossRef]

85. Steiniger, S.; Bocher, E. An overview on current free and open source desktop GIS developments. Int. J. Geogr. Inf. Sci. 2009, 23, 1345-1370. [CrossRef]

86. Friedrich, C. Comparison of ArcGIS and QGIS for Applications in Sustainable Spatial Planning; Universität Wien: Wien, Austria, 2014.

87. Khan, S.; Aaqib, S.M. Empirical Evaluation of ArcGIS with Contemporary Open Source Solutions-A Study. Int. J. Adv. Res. Sci. Eng. 2017, 6, 724-736.

88. Khan, S.; Mohiuddin, K. Evaluating the parameters of ArcGIS and QGIS for GIS Applications. Int. J. Adv. Res. Sci. Eng. 2018, 7, 582-594.

89. Dobesova, Z. Cartoevaluation method for assessment of gis software. Geod. Cartogr. 2013, 39, 164-170. [CrossRef]

90. Carver, S.J. Integrating multi-criteria evaluation with geographical information systems geographical information systems. Int. J. Geogr. Inf. Syst. 1991, 5, 321-339. [CrossRef]

91. Glackin, S. Redeveloping the Greyfields With Envision: Using Participatory Support Systems To Reduce Urban Sprawl in Australia. Eur. J. Geogr. 2013, 3, 6-22.

Publisher's Note: MDPI stays neutral with regard to jurisdictional claims in published maps and institutional affiliations.

(C) 2020 by the authors. Licensee MDPI, Basel, Switzerland. This article is an open access article distributed under the terms and conditions of the Creative Commons Attribution (CC BY) license (http://creativecommons.org/licenses/by/4.0/). 